\title{
Opioid Related Deaths in Ontario Between 1991 and 2010
}

A Report by the Ontario Drug Policy Research Network

Project Team

Tara Gomes, MHSc

Diana Martins, MSc

Samantha Singh, BSc

Muhammad Mamdani, PharmD, MPH

Irfan Dhalla, MD, MSc

Michael Paterson, MSc

Mina Tadrous, PharmD, MS

David Juurlink, MD, PhD

November 2014 


\section{CONTACT INFORMATION}

Ontario Drug Policy Research Network

St Michael's Hospital

30 Bond Street

Toronto ON

M5B 1W8

info@odprn.ca

www.odprn.ca

\section{ACKNOWLEDGMENTS}

This study was supported by grants from the Ontario Ministry of Health and Long-Term Care (MOHLTC) Health System Research Fund and Drug Innovation Fund.

The work was supported by the Institute for Clinical Evaluative Sciences (ICES), which is funded by an annual grant from the Ontario Ministry of Health and Long-Term Care (MOHLTC). The opinions, results and conclusions reported in this paper are those of the authors and are independent from the funding sources. No endorsement by ICES or the Ontario MOHLTC is intended or should be inferred.

We thank Dan Cass and Nav Persaud at the Office of the Chief Coroner for Ontario for project facilitation and their assistance with data retrieval. 


\section{TABLE OF CONTENTS}

BACKROUNDD




\section{BACKGROUND}

Opioid analgesics are widely prescribed medications used for the treatment of pain. However, the rate of opioid prescribing and the number of deaths related to opioid overdoses have increased dramatically over the last two decades in Ontario, highlighting safety concerns around these commonly prescribed analgesics. ${ }^{1,2}$

Past research found that the introduction of new opioid products led to increases in opioid-related deaths between 1991 and 2004. Specifically, following the introduction of a long-acting oxycodone formulation to the Ontario provincial drug formulary in January 2000 , a substantial increase in the rate of oxycodone-related mortality and overall opioid-related mortality was noted. Most of these deaths were found to be accidental. ${ }^{1}$

Premature deaths related to opioid overdoses have resulted in an extraordinary number of unnecessary potential years of life lost. In 2010, nearly one out of every eight deaths among individuals aged 25 to 34 years involved an opioid, demonstrating the public health impact of opioid misuse, and the need for change in the safe use of these medications. ${ }^{2}$

Given the changes in prescribing trends of opioids, along with the increasing rate of opioid-related deaths, updated data is needed to understand the types of opioids that are most commonly involved in opioid overdose deaths as well as the manner of these deaths.

\section{OBJECTIVE}

This report describes the specific opioids that are involved in opioid overdose deaths and the characteristics of the individuals who died of opioid-related causes, in Ontario. 


\section{METHODS}

\section{SETTING}

We conducted a cross-sectional study among individuals who died of opioid-related causes between January 1991 and December 2010, using data obtained from the Office of the Chief Coroner (OCC) for Ontario. Deaths abstracted from the OCC for Ontario were deemed opioid-related by the coroner if post-mortem toxicological analysis revealed opioid concentrations sufficiently high to cause death, or if a combination of drugs (including at least one opioid at clinically significant levels) contributed to death. Deaths involving heroin (identified on the police record or by the presence of 6 -

monoacetylmorphone post-mortem toxicological analysis) with no other opioid present at time of death were excluded. This method has been used in previous studies in this area. $^{1,2}$

\section{DATA SOURCES}

Information regarding opioid-related deaths was abstracted from records of all deaths involving drugs or alcohol from the OCC for Ontario. In Ontario, all deaths that are sudden and unexpected, or unnatural are investigated by the OCC to ascertain cause and manner of death. The Ontario Health Insurance Plan Registered Persons Database (RPDB) was used to determine the demographic characteristics of all Ontarians who died of opioid-related causes between 1991 and 2010. These datasets were linked using unique, encoded identifiers and analyzed at the ICES.

\section{STUDY DRUGS}

- Opioids: Morphine or heroin (alone or both), codeine, methadone, oxycodone, fentanyl, hydromorphone, others (hydrocodone, meperidine, propoxyphene, pentazocine, anileridine) and undetermined (no flag for any of the opioids listed).

- Alcohol: Ethanol.

- Other drugs: cocaine, GHB (gammahydroxybutyrate), ketamine, benzodiazepines, cyclic antidepressants, neuroleptics, anti-epileptics, anticholinergics, antihistamines, barbiturates, stimulants. 


\section{KEY FINDINGS}

\section{Characteristics of people who died of opioid-related causes in Ontario, 1991-2010 \\ (Table 1 and Table 2)}

- Between 1991 and 2010, 5935 deaths from opioid-related causes were identified in charts abstracted from the OCC for Ontario, 64.4\% ( $\mathrm{N}=3822)$ of which were men.

- The age at death ranged between 0 and 97 , with a median age at death of 42 years (interquartile range [IQR] 34-50 years).

- The manner of death was deemed by the coroner to be accidental in $60.5 \%$ $(\mathrm{N}=3,592)$ of deaths, suicide in $20.3 \%(\mathrm{~N}=1202)$ of deaths and other (undetermined, homicide or missing) in $19.2 \%$ ( $\mathrm{N}=1141)$ of deaths.

- During the 20-year period, the majority of deaths involved a single opioid (64.3\%; $\mathrm{N}=3819$ ). The opioids most commonly involved in single opioid deaths were:

O Morphine or heroin (or both) $(24.7 \% ; \mathrm{N}=943)$

O Oxycodone $(24.6 \% ; \mathrm{N}=938)$

O Methadone (15.5\%; $\mathrm{N}=590)$

O Codeine (12.8\%; $\mathrm{N}=489$ )

- A single opioid was present in most opioid-related deaths, for all manner of deaths (65.4\% accidental, $67.8 \%$ suicide and $63.6 \%$ other).

- Alcohol was present in toxicological screens for $41.4 \%(\mathrm{~N}=2459)$ of the opioid-related deaths.

- Among the cases where multiple opioids were responsible for death ( $\mathrm{N}=2116)$, the majority had codeine (65.3\%; $\mathrm{N}=1381)$ and morphine/heroin $(64.0 \% ; \mathrm{N}=1355)$ involved. This was followed by oxycodone (29.3\%; $\mathrm{N}=620)$.

- Benzodiazepine use was present among half (50.5\%; N=2995) of all opioid-related deaths. The second most common drug present was cocaine $(22.9 \% ; \mathrm{N}=1358)$.

\section{Characteristics of people who died of opioid-related causes in Ontario, 2006-2010 \\ (Table 2 and Table 3 )}

- $40.2 \%(\mathrm{~N}=2383)$ of all opioid-related deaths in the last 20 years (between 1991 and 2010) occurred in the most recent 5 years (2006 to 2010).

- The age at death ranged between 1 and 92, with a median age at death of 44 years (IQR 35-51 years).

- The majority $(63.2 \% ; \mathrm{N}=1505)$ of decedents were men. 
- The manner of death was deemed by the coroner to be accidental in $69.2 \%$ ( $N=1659)$ of deaths, suicide in $15.7 \%(\mathrm{~N}=375)$ of deaths and other (undetermined, homicide or missing) in $14.6 \%(\mathrm{~N}=249)$ deaths.

- The majority of deaths involved a single opioid (66.6\%; $\mathrm{N}=1588$ ). The opioids most commonly involved in these deaths were:

O Oxycodone (38.5\%; $\mathrm{N}=612$ )

$\mathrm{O}$ Morphine or heroin (or both) $(17.8 \% ; \mathrm{N}=283)$

O Methadone (14.6\%; $\mathrm{N}=232$ )

O Fentanyl (12.1\%; $\mathrm{N}=192)$

- A single opioid was present in most opioid-related deaths, regardless of the manner of death (66.1\% accidental, $68.3 \%$ suicide and $67.3 \%$ other).

- Alcohol was present in toxicological screens for $38.6 \%(\mathrm{~N}=920)$ of the opioid-related deaths.

- Among the cases where multiple opioids were responsible for death ( $N=795)$, the majority had codeine (50.8\%; $\mathrm{N}=404$ ) and morphine/heroin (59.5\%; $\mathrm{N}=473$ ) involved. This was followed by oxycodone (44.7\%; $\mathrm{N}=355)$.

- A benzodiazepine was present in almost half (46.7\%; $\mathrm{N}=1112)$ of cases. The second most common drug present was cocaine $(25.2 \% ; \mathrm{N}=600)$. 


\section{Tables}

Table 1

Characteristics of people who died of opioid-related causes in Ontario, 1991 to 2010

\begin{tabular}{|c|c|}
\hline Characteristic & $\begin{array}{c}\text { Number of Opioid-Related } \\
\text { Deaths (\%) }\end{array}$ \\
\hline Total Number of Deaths & 5,935 \\
\hline Age (median, IQR) & $42(34-50)$ \\
\hline Gender (male) & $3,822(64.4 \%)$ \\
\hline \multicolumn{2}{|l|}{ Manner of death } \\
\hline Accidental & $3,592(60.5 \%)$ \\
\hline Suicide & $1,202(20.3 \%)$ \\
\hline Other $^{1}$ & $1,141(19.2 \%)$ \\
\hline Multiple opioids associated with death & $2,116(35.7 \%)$ \\
\hline Morphine or heroin (or both) & $1,355(64.0 \%)$ \\
\hline Codeine & $1,381(65.3 \%)$ \\
\hline Methadone & $344(16.3 \%)$ \\
\hline Oxycodone & $620(29.3 \%)$ \\
\hline Fentanyl & $216(10.2 \%)$ \\
\hline Hydromorphone & $340(16.1 \%)$ \\
\hline Others & $436(20.6 \%)$ \\
\hline Single opioid associated with death & $3,819(64.3 \%)$ \\
\hline Morphine or heroin (or both) & $943(24.7 \%)$ \\
\hline Codeine & 489 (12.8\%) \\
\hline Methadone & $590(15.5 \%)$ \\
\hline Oxycodone & $938(24.6 \%)$ \\
\hline Fentanyl & $273(7.2 \%)$ \\
\hline Hydromorphone & $270(7.1 \%)$ \\
\hline Others & $239(6.3 \%)$ \\
\hline Undetermined opioid involved in death & $77(2.0 \%)$ \\
\hline Alcohol present & 2,459 (41.4\%) \\
\hline \multicolumn{2}{|l|}{ Other drugs present } \\
\hline Cocaine & $1,358(22.9 \%)$ \\
\hline $\mathrm{GHB}^{2}$ & $7(0.1 \%)$ \\
\hline Ketamine & $12(0.2 \%)$ \\
\hline Benzodiazepines & 2,995 (50.5\%) \\
\hline Cyclic antidepressants & $1,141(19.2 \%)$ \\
\hline AntisychoticsNeuroleptics & $526(8.9 \%)$ \\
\hline Anti-epileptics & 332 (5.6\%) \\
\hline Anticholinergics & $112(1.9 \%)$ \\
\hline Antihistamines & $1,185(20.0 \%)$ \\
\hline Barbiturates & $257(4.3 \%)$ \\
\hline Stimulants & $210(3.5 \%)$ \\
\hline
\end{tabular}


Table 2

Number of deaths due to single or multiple opioids in Ontario, by manner of death

\begin{tabular}{|c|c|c|c|}
\hline & \multicolumn{3}{|c|}{ Manner of Death } \\
\hline & $\begin{array}{c}\text { Accidental } \\
\text { N (\%) }\end{array}$ & $\begin{array}{c}\text { Suicide } \\
\text { N (\%) }\end{array}$ & $\begin{array}{l}\text { Other }^{1} \\
\text { N (\%) }\end{array}$ \\
\hline 1991-2010 & 3,592 & 1,202 & 1,141 \\
\hline Multiple opioids & $1,314(36.6 \%)$ & $387(32.2 \%)$ & 415 (36.4\%) \\
\hline Single opioid & $2,278(65.4 \%)$ & $815(67.8 \%)$ & $726(63.6 \%)$ \\
\hline 2006-2010 & 1,659 & 375 & 349 \\
\hline Multiple opioids & 562 (33.9\%) & 119 (31.7\%) & $114(32.7 \%)$ \\
\hline Single opioid & $1,097(66.1 \%)$ & $256(68.3 \%)$ & 235 (67.3\%) \\
\hline
\end{tabular}

${ }^{1}$ Other includes homicide, undetermined or missing entries 
Table 3

Characteristics of people who died of opioid-related causes in Ontario, 2006 to 2010

\begin{tabular}{|c|c|}
\hline Characteristic & $\begin{array}{c}\text { Number of Opioid-Related } \\
\text { Deaths (\%) }\end{array}$ \\
\hline Total Number of Death & 2,383 \\
\hline Age (median, IQR) & $44(35-51)$ \\
\hline Gender (Male) & $1,505(63.2 \%)$ \\
\hline \multicolumn{2}{|l|}{ Manner of death } \\
\hline Accidental & $1,659(69.2 \%)$ \\
\hline Suicide & $375(15.7 \%)$ \\
\hline Other $^{1}$ & 249 (14.6\%) \\
\hline Multiple opioids associated with death & 795 (33.4\%) \\
\hline Morphine or heroin (or both) & $473(59.5 \%)$ \\
\hline Codeine & $404(50.8 \%)$ \\
\hline Methadone & $148(18.6 \%)$ \\
\hline Oxycodone & $355(44.7 \%)$ \\
\hline Fentanyl & $159(20.0 \%)$ \\
\hline Hydromorphone & $195(24.5 \%)$ \\
\hline Others & $94(11.8 \%)$ \\
\hline Single opioid associated with death & $1,588(66.6 \%)$ \\
\hline Morphine or heroin (or both) & $283(17.8 \%)$ \\
\hline Codeine & $62(3.9 \%)$ \\
\hline Methadone & $232(14.6 \%)$ \\
\hline Oxycodone & $612(38.5 \%)$ \\
\hline Fentanyl & $192(12.1 \%)$ \\
\hline Hydromorphone & $155(9.8 \%)$ \\
\hline Others & $24(1.5 \%)$ \\
\hline Undetermined opioid involved in death & $28(1.8 \%)$ \\
\hline Alcohol present & $920(38.6 \%)$ \\
\hline \multicolumn{2}{|l|}{ Other drugs present } \\
\hline Cocaine & $600(25.2 \%)$ \\
\hline $\mathrm{GHB}^{2}$ & $\leq 5$ \\
\hline Ketamine & $\leq 5$ \\
\hline Benzodiazepine & $1,112(46.7 \%)$ \\
\hline Tricyclic antidepressantss & $352(14.8 \%)$ \\
\hline Neuroleptics & $229(9.6 \%)$ \\
\hline Anti-epileptics & $134(5.6 \%)$ \\
\hline Anticholinergics & $13(0.6 \%)$ \\
\hline Antihistamines & $432(18.1 \%)$ \\
\hline Barbiturates & $35(1.5 \%)$ \\
\hline Stimulants & $135(5.7 \%)$ \\
\hline
\end{tabular}

Note: IQR = interquartile range

Note: In compliance with ICES privacy policies, values $<6$ are suppressed.

${ }^{1}$ Other includes homicide, undetermined or missing entries

${ }^{2}$ Gammahydroxybutyrate 


\section{CONCLUSIONS}

Between 1991 and 2010, there were 5,935 deaths from opioid-related causes identified in charts abstracted from the OCC for Ontario. The majority of these deaths occurred among men, involved a single opioid, and were deemed as accidental. The age at death ranged from 0 to 97 years of age and the median age of death was 42 years (IQR 34-50 years). The opioids most commonly involved in opioid-related deaths were morphine and or heroin (or the two combined), followed by oxycodone, methadone and codeine. During the last five years of the study period (between 2006 and 2010), oxycodone was the opioid most commonly involved in overdose deaths involving a single opioid, followed by morphine, heroin, methadone, and fentanyl. For overdose deaths where multiple opioids were involved, the most commonly involved opioids were codeine, morphine or heroin (or both), followed by oxycodone. A higher proportion of oxycodone and a lower proportion of codeine were involved in deaths with multiple opioids in the last five years. The majority of opioid-related deaths involved another medications or alcohol. Benzodiazepine use was present among approximately half of all opioid-related deaths.

These findings suggest that increased awareness of the dangers associated with opioid use and concomitant use of these drugs with other products may help prevent opioid overdose deaths in Ontario. In an effort to ensure appropriate use of opioids, the Narcotics Safety and Awareness Act was introduced in Ontario in 2010. Whether the Act and related interventions have reduced opioid-related mortality will be the subject of future research. 


\section{REFERENCES}

${ }^{1}$ Dhalla I, Mamdani M, Sivlotti M, Kopp A, Qureshi O, Juurlink D. Prescribing of opioid analgesics and related mortality before and after the introduction of long-acting oxycodone. CMAJ 2011; 181; 891-896.

${ }^{2}$ Gomes T, Mamdani M, Dhalla I, Cornish S, Paterson M, Juurlink D. The burden of premature opioid-related mortality. Addiction 2014. doi:10.111/add.12598. 